The INL is a

U.S. Department of Energy

National Laboratory

operated by

Battelle Energy Alliance

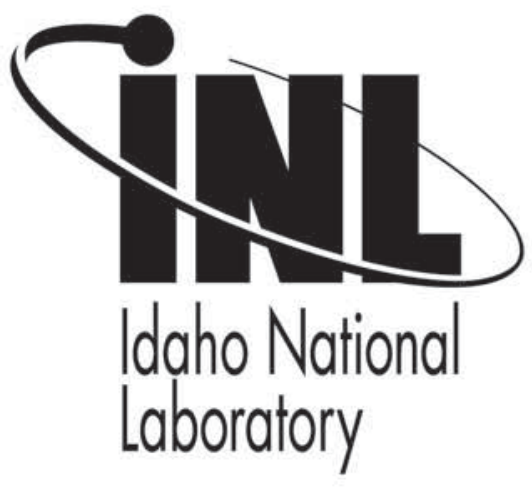

\section{New Sensors for the Advanced Test Reactor National Scientific User Facility}

\section{ANIMMA International Conference}

\author{
Joy L. Rempe \\ Darrell L. Knudson \\ Keith G. Condie \\ Joshua E. Daw \\ Heng Ban \\ Brandon Fox \\ Gordon E. Kohse
}

\section{June 2009}

This is a preprint of a paper intended for publication in a journal or proceedings. Since changes may be made before publication, this preprint should not be cited or reproduced without permission of the author. This document was prepared as an account of work sponsored by an agency of the United States Government. Neither the United States Government nor any agency thereof, or any of their employees, makes any warranty, expressed or implied, or assumes any legal liability or responsibility for any third party's use, or the results of such use, of any information, apparatus, product or process disclosed in this report, or represents that its use by such third party would not infringe privately owned rights. The views expressed in this paper are not necessarily those of the United States Government or the sponsoring agency. 


\title{
New sensors for the Advanced Test Reactor National Scientific User Facility
}

\author{
Joy L. Rempe, Darrell L. Knudson, Keith G. Condie, Joshua E. Daw, Heng Ban, \\ Brandon Fox, and Gordon E. Kohse
}

\begin{abstract}
A key component of the Advanced Test Reactor (ATR) National Scientific User Facility (NSUF) effort is to develop and evaluate in-pile instrumentation capable of providing real-time measurements of key parameters during irradiation. This paper describes the strategy for identifying and prioritizing instrumentation needs and the program initiated to develop new or enhanced sensors to address these needs. Accomplishments from this program are illustrated by describing new sensors now available to users of the ATR NSUF with data from irradiation tests using these sensors. In addition, progress is reported on current research efforts to provide users advanced methods for detecting temperature, fuel thermal conductivity, and changes in sample geometry.
\end{abstract}

Index Terms - In-pile detectors, radiation resistant sensors

\section{INTRODUCTION}

$\mathrm{T}$ HE U.S. Department of Energy (DOE) designated the Advanced Test Reactor (ATR) as a National Scientific User Facility (NSUF) in April 2007 to support U.S. research in nuclear science and technology. By supporting users from universities, laboratories, and industry, the ATR will support basic and applied nuclear research and development and advance the nation's energy security needs. A key component of the ATR NSUF effort is to develop and implement in-pile instrumentation capable of providing real-time measurements of key parameters during irradiation. This paper describes the strategy for identifying instrumentation needed for ATR irradiation tests and the program initiated to obtain these sensors. New sensors developed from this effort are identified; and the progress of other development efforts is summarized.

Manuscript received May 12, 2009. Work supported by the US Department of Energy, Office of Nuclear Energy, Science, and Technology, under DOE-NE Idaho Operations Office Contract DE AC07 05ID14517.

J. Rempe,* D. Knudson, K. Condie and J. Daw are with the Idaho National Laboratory, P.O. Box 1625, MS 3840, Idaho Falls, ID, USA (phone: 208-526-2897; fax: 208-526-2930; e-mail: Joy.Rempe@inl.gov).

Gordon Kohse is with the Nuclear Reactor Laboratory, Massachusetts Institute of Technology, 77 Massachusetts Avenue, Cambridge, MA, USA (email: KOHSE@mit.edu).

Brandon Fox and Heng Ban are with the Mechanical Engineering Department, Utah State University, 4130 Old Main Hill Logan, UT 843224130 USA, (e-mail: heng.ban@usu.edu).

\section{A. ATR Design and Irradiation Capabilities}

The ATR is a versatile tool for conducting nuclear reactor, nuclear physics, reactor fuel, and structural material irradiation experiments [1].

The ATR's maximum power rating is $250 \mathrm{MW}_{\text {th }}$ with a maximum unperturbed thermal neutron flux of $1 \times 10^{15} \mathrm{n} / \mathrm{cm}^{2}-\mathrm{s}$ and a maximum fast neutron flux of $5 \times 10^{14} \mathrm{n} / \mathrm{cm}^{2}-\mathrm{s}$. Because most contemporary experimental objectives do not require the upper limits of its capability, the ATR typically operates at lower power levels (nominally $110 \mathrm{MW}_{\text {th }}$ ). The ATR is available over $70 \%$ of the year, in cycles that typically range from 6 to 8 weeks, with outages lasting one or two weeks. The ATR is cooled by pressurized (2.5 MPa/360 psig) water that enters the reactor vessel bottom at an average temperature of $52{ }^{\circ} \mathrm{C}\left(126^{\circ} \mathrm{F}\right)$, flows up outside cylindrical tanks that support and contain the core, passes through concentric thermal shields into the open part of the vessel, then flows down through the core to a flow distribution tank below the core. When the reactor is operating at full power, the primary coolant exits the vessel at $71^{\circ} \mathrm{C}\left(160^{\circ} \mathrm{F}\right)$.

As shown in Fig. 1, the ATR core consists of 40 curved plate fuel elements in a serpentine arrangement around a $3 \times 3$ array of primary testing locations, including nine large highintensity neutron flux traps. The unique ATR control device design permits large power variations among its nine flux traps using a combination of control cylinders (drums) and neck shim rods. The beryllium control cylinders contain hafnium plates that can be rotated toward and away from the core. Hafnium shim rods, which withdraw vertically, are inserted or withdrawn for minor power adjustments. Within bounds, the power level in each corner lobe of the reactor can be controlled independently to allow for different power and flux levels in the four corner lobes during the same operating cycle. The ratio of fast to thermal flux can be varied from 0.1 to 1.0. In addition to the nine large volume (up to $1.22 \mathrm{~m}$ long and up to $0.13 \mathrm{~m}$ diameter) high-intensity neutron flux traps, there are 66 irradiation positions inside the reactor core reflector tank, and two capsule irradiation tanks outside the core with 34 low-flux irradiation positions. 


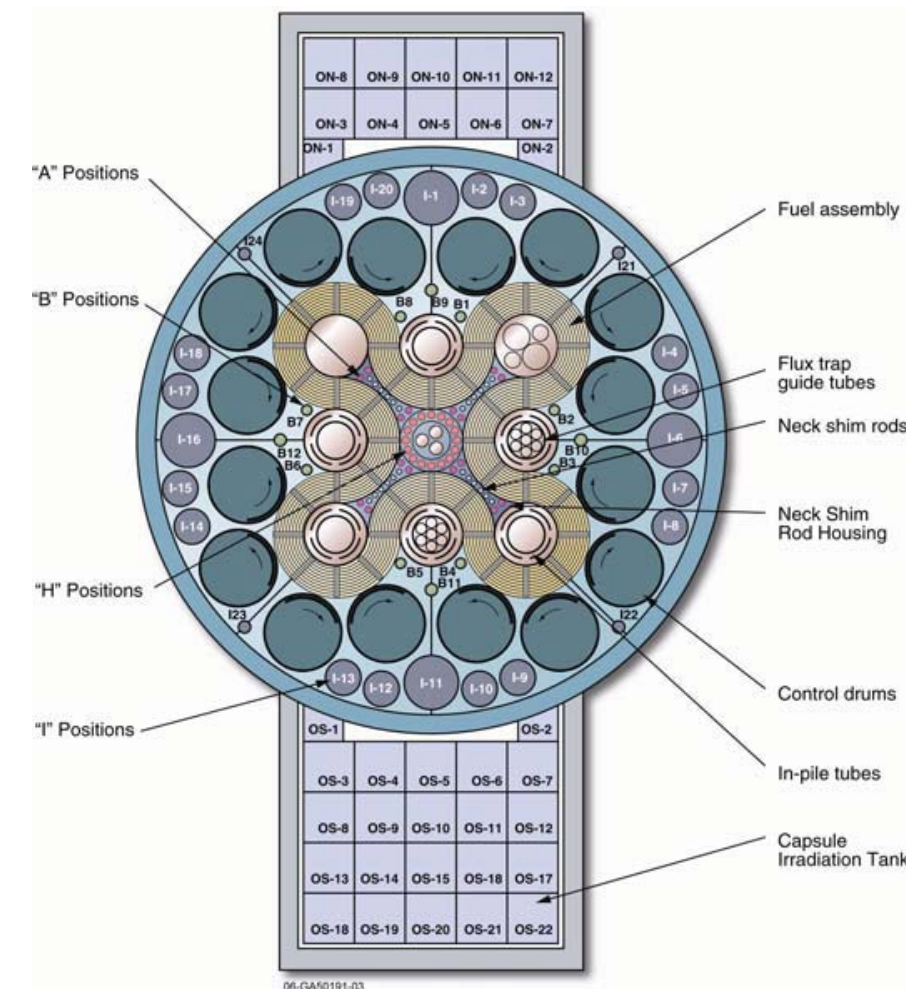

Fig. 1. ATR core cross section showing irradiation locations.

There are three ATR test assembly configurations:

- Static Capsule Experiment - These capsules may contain a number of small samples or engineered components. Static capsule experiments may be sealed or may contain material that can be in contact with the ATR primary coolant (such capsules are in an open configuration without being sealed). Capsules may be any length, up to $122 \mathrm{~cm}$ (48 in.) and may be irradiated in any core position, including the flux traps. Irradiation temperature may be selected by providing a gas gap in the capsule with a known thermal conductance. Peak temperatures may be measured using a series of melt wires, temperature-sensitive paint spots, or silicon carbide temperature monitors. Accumulated neutron fluences may be verified using flux wires.

- Instrumented Lead Experiment - Active control of experiments and data from test capsules during irradiation is achieved using core positions with instrumentation cables and temperature control gases in ATR instrumented lead experiments. Such experiments can have instrumentation, such as thermocouples, connected to individual capsules or single specimens. This instrumentation can be used to control and sample conditions within the capsule. For example, temperature control in individual zones is performed by varying the gas mixture (typically helium and neon) in the gas gap that thermally links the capsule to the water-cooled reactor structure. In addition to temperature, instrumented lead experiments have been used to monitor the gas around the test specimen. In a fueled experiment, the presence of fission gases due to fuel failures or oxidation can be detected via gas chromatography. Instrument leads allow real time display of experimental parameters in the control room.
- Pressurized Water Loop Experiment - Five of the nine ATR flux traps used for materials and fuels testing are equipped with pressurized water loops (at the NW, N, SE, $\mathrm{SW}$, and $\mathrm{W}$ locations). A sixth loop will be operational in 2010. Each of the water loops can be operated at different temperatures, pressures, flow rates, or water chemistry requirements. These loops can operate above the standard temperatures and pressure of a commercial PWR power plant. The great advantage of loop tests is the ease with which a variety of samples can be subjected to conditions specified for any PWR design. Each ATR pressurized loop is instrumented to measure and control coolant flows (both helium and water), temperatures, pressures and sample test data.

Clearly, the ATR design offers unique advantages for testing. With additional in-pile instrumentation to support these testing capabilities, the features offered by this reactor user facility can be even more fully utilized.

\section{B. Addressing ATR User Needs for Enhanced Instrumentation}

Despite its long history for developing highly specialized instrumentation to meet demands of customers conducting unique tests in one-of-a-kind test facilities, INL instrumentation research funding decreased significantly in the 1980s when large nuclear test facility programs ended. Until recently, ATR irradiations relied primarily on commercial vendors for instrumentation. In 2004, an instrumentation effort was restarted that allowed staff at INL's High Temperature Test Laboratory (HTTL) to develop unique instrumentation required for ATR irradiations while prior sensor fabrication and evaluation expertise were still available. Currently, several INL efforts are underway to enhance in-pile instrumentation for ATR users. This section describes the approach being used by INL to identify and prioritize ATR in-pile instrumentation development research.

INL efforts to enhance ATR instrumentation began by first completing a review of references (e.g., [2]-[11]) to identify instrumentation available to users at other test reactors located in the U.S. and abroad. Table I summarizes results from this review. The column labeled "Technology Available at ATR" indicates the types of sensors currently available to ATR users. The column "Proposed Advanced Technology" includes two categories: "Available at Other Reactors" identifies several technologies employed at other test reactors that could be adapted to enhance ATR instrumentation capabilities and "Proposed Instrumentation Advancement" identifies developmental or non-nuclear technologies that could be used in irradiation tests. Blue text denotes the instrumentation currently being pursued as part of ATR NSUF research activities, and red text denotes new instrumentation developed by INL and deployed in the ATR. Note that many of these instrumentation development efforts are in collaboration with other organizations. The instrumentation currently being evaluated for the ATR NSUF (denoted by blue text in Table I) was selected based on anticipated user needs and 'technology readiness' (providing ATR users needed instrumentation in the near-term). 
Although not discussed in this paper, efforts are underway to develop standardized instrumented lead and PWR test train designs that incorporate new ATR NSUF instrumentation and instrumentation currently used at other test reactors. Data from initially deployed standardized test vehicles will be used to validate the performance of developmental instrumentation.

\section{REPRESENTATIVE DEVELOPMENT EFFORTS}

Selected examples of efforts to develop new methods for detecting temperature and dimensional changes during ATR irradiations are summarized in this section.

TABLE I

INSTRUMENTATION AVAILABLE AT ATR AND OTHER TEST REACTORS

\begin{tabular}{|c|c|c|c|c|c|c|}
\hline \multirow[b]{2}{*}{ Parameter } & \multicolumn{3}{|c|}{ Parameter } & \multirow[b]{2}{*}{ ATR Technology } & \multicolumn{2}{|c|}{ Proposed Advanced Technology } \\
\hline & $\begin{array}{l}\text { Static } \\
\text { Capsule }\end{array}$ & $\begin{array}{l}\text { Instr. } \\
\text { Lead }\end{array}$ & $\begin{array}{l}\text { PWR } \\
\text { Loop }\end{array}$ & & $\begin{array}{l}\text { Available at Other } \\
\text { Reactors }\end{array}$ & Developmental \\
\hline \multirow[t]{2}{*}{ Temperature } & $\sqrt{ }$ & $\sqrt{ }$ & $\sqrt{ }$ & $\begin{array}{l}\text {-Melt wires (peak) } \\
\text {-Paint spots (peak) }\end{array}$ & $\begin{array}{l}\text {-SiC Temperature } \\
\text { Monitors (range) }\end{array}$ & -Wireless (range) \\
\hline & & $\sqrt{ }$ & $\sqrt{ }$ & $\begin{array}{l}\text {-Thermocouples (Type N, K, } \\
\text { C, and HTIR-TCs) }\end{array}$ & & - Fiber Optics \\
\hline $\begin{array}{l}\text { Thermal } \\
\text { Conductivity }\end{array}$ & & $\sqrt{ }$ & $\sqrt{ }$ & -Out-of-pile examinations & $\begin{array}{l}\text {-Degradation using signal } \\
\text { changes in thermocouples }\end{array}$ & -Hot wire techniques \\
\hline \multirow[t]{2}{*}{ Fluence (neutron) } & $\sqrt{ }$ & $\sqrt{ }$ & $\sqrt{ }$ & -Flux wires $(\mathrm{Fe}, \mathrm{Ni}, \mathrm{Nb})$ & -Activating foil dosimeters & \\
\hline & & $\sqrt{ }$ & $\sqrt{ }$ & & $\begin{array}{l}\text {-Self-Powered Neutron } \\
\text { Detectors (SPNDs) } \\
\text {-Subminiature fission } \\
\text { chambers }\end{array}$ & -Moveable SPNDs \\
\hline Gamma Heating & & $\sqrt{ }$ & $\sqrt{ }$ & & $\begin{array}{l}\text {-Degradation using signal } \\
\text { changes in thermocouples }\end{array}$ & \\
\hline \multirow[t]{2}{*}{ Dimensional } & $\sqrt{ }$ & $\sqrt{ }$ & $\sqrt{ }$ & -Out-of-pile examinations & & \\
\hline & & $\sqrt{ }$ & $\sqrt{ }$ & & $\begin{array}{l}\text {-LVDTs (stressed and } \\
\text { unstressed) } \\
\text {-Diameter gauge } \\
\text {-Hyper-frequency resonant } \\
\text { cavities }\end{array}$ & $\begin{array}{l}\text { - Ultrasonic } \\
\text { Transducers } \\
\text {-Fiber Optics }\end{array}$ \\
\hline $\begin{array}{l}\text { Fission Gas } \\
\text { (Amount, } \\
\text { Composition) }\end{array}$ & & $\sqrt{ }$ & $\sqrt{ }$ & $\begin{array}{l}\text {-Gas Chromatography } \\
\text {-Pressure sensors } \\
\text { - Gamma detectors } \\
\text { - Sampling }\end{array}$ & $\begin{array}{l}\text {-LVDT-based pressure } \\
\text { gauge }\end{array}$ & $\begin{array}{l}\text {-Acoustic } \\
\text { measurements with } \\
\text { high-frequency } \\
\text { echography }\end{array}$ \\
\hline Loop Pressure & & & $\sqrt{ }$ & $\begin{array}{l}\text {-Differential pressure } \\
\text { transmitters } \\
\text {-Pressure gauges with } \\
\text { impulse lines }\end{array}$ & & \\
\hline Loop Flowrate & & & $\sqrt{ }$ & $\begin{array}{l}\text {-Flow venturis } \\
\text {-Orifice plates }\end{array}$ & & \\
\hline $\begin{array}{l}\text { Loop Water } \\
\text { Chemistry }\end{array}$ & & & $\sqrt{ }$ & -Off-line sampling /analysis & & \\
\hline Crud Deposition & & & $\sqrt{ }$ & -Out-of-pile examinations & $\begin{array}{l}\text {-Diameter gauge with } \\
\text { neutron detectors and } \\
\text { thermocouples }\end{array}$ & \\
\hline $\begin{array}{l}\text { Crack Growth } \\
\text { Rate }\end{array}$ & & & $\sqrt{ }$ & & $\begin{array}{l}\text {-Direct Current Potential } \\
\text { Drop Technique }\end{array}$ & \\
\hline
\end{tabular}

${ }^{a}$ Blue text denotes instrumentation being investigated for ATR applications; red text denotes new instrumentation currently deployed at the ATR.

a a Type C thermocouple use requires a "correction factor" to correct for decalibration during irradiation. 


\section{A. Temperature}

Because of the importance of this key parameter, new methods for detecting sample temperature during irradiation are required. This section summarizes INL efforts to develop unique new thermocouples that resist decalibration due to high temperatures and neutron transmutation in instrumented lead and loop tests and silicon carbide temperature monitors for static capsule tests. Although not discussed in this paper, INL is also collaborating with Luna Innovations to explore the use of fiber optics as a non-contact temperature sensor.

\section{1) High Temperature Irradiation Resistant}

Thermocouples (HTIR-TCs)

Commercially-available thermocouples drift due to degradation at high temperatures (above $1100{ }^{\circ} \mathrm{C}$ ) or due to transmutation of thermocouple components. Thermocouples are needed that can withstand both high temperature and high radiation environments. To address this need, INL developed a High Temperature Irradiation Resistant ThermoCouple (HTIR-TC) design that contains commercially-available doped molybdenum paired with a niobium alloy. Battelle Energy Alliance (BEA), the operating contractor for INL, has filed a patent application for this technology, and INL now offers the sensors to ATR and other test reactor customers. HTIR-TC component materials were selected based on data obtained from materials interaction tests, ductility investigations, and resolution evaluations (see [12] through [14]). To demonstrate HTIR-TC long duration performance, long-term testing, in which thermocouples are held at elevated temperatures (from $1200{ }^{\circ} \mathrm{C}$ to $1800{ }^{\circ} \mathrm{C}$ ) for up to 6 months, was performed. The $1200{ }^{\circ} \mathrm{C}$ test included nineteen commercially-available Type $\mathrm{N}$ thermocouples, three commercially-available Type K thermocouples, and nine INLdeveloped swaged HTIR-TCs (see Fig. 2).

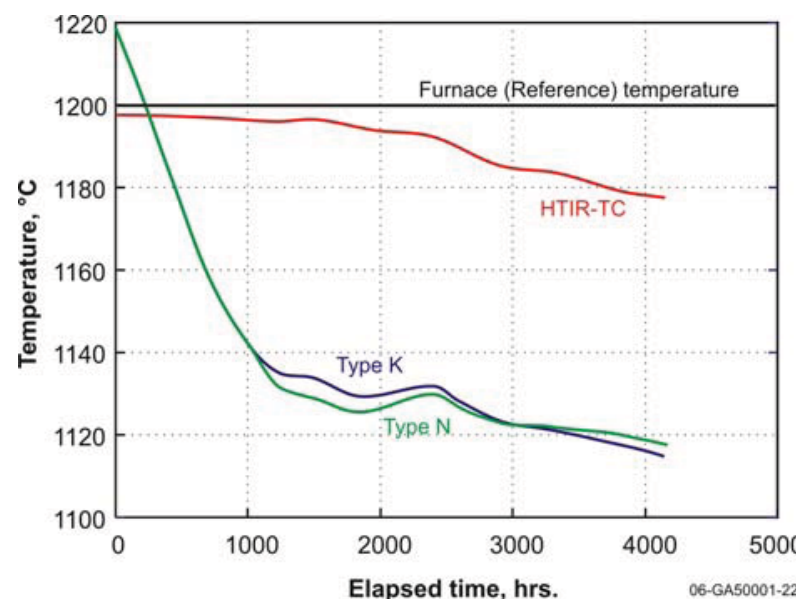

Fig. 2. Representative thermocouple response in $1200{ }^{\circ} \mathrm{C}$ tests.

As indicated in Fig. 2, some Type $\mathrm{K}$ and $\mathrm{N}$ thermocouples drifted by over $100{ }^{\circ} \mathrm{C}$ or $8 \%$. Much smaller drifts (typically less than $20^{\circ} \mathrm{C}$ or $2 \%$ ) were observed in the INL-developed HTIR-TCs. As documented in [12], similar drifts (2\%) were observed in HTIR-TCs in a long duration (4000 hour) test completed at $1400{ }^{\circ} \mathrm{C}$. Results from higher-temperature (e.g., $1500^{\circ} \mathrm{C}$ and $1800{ }^{\circ} \mathrm{C}$ ) evaluations in a vacuum furnace installed at the HTTL suggest that "loose assembly" HTIRTCs exhibit superior performance to "swaged" and "drawn" HTIR-TC designs at higher temperatures. As shown in Fig. 3, the loose assembly HTIR-TC drifted approximately $0.1 \%$ whereas the drawn and swaged designs drifted by $2 \%$ during a 1000 hour test at $1500^{\circ} \mathrm{C}$.

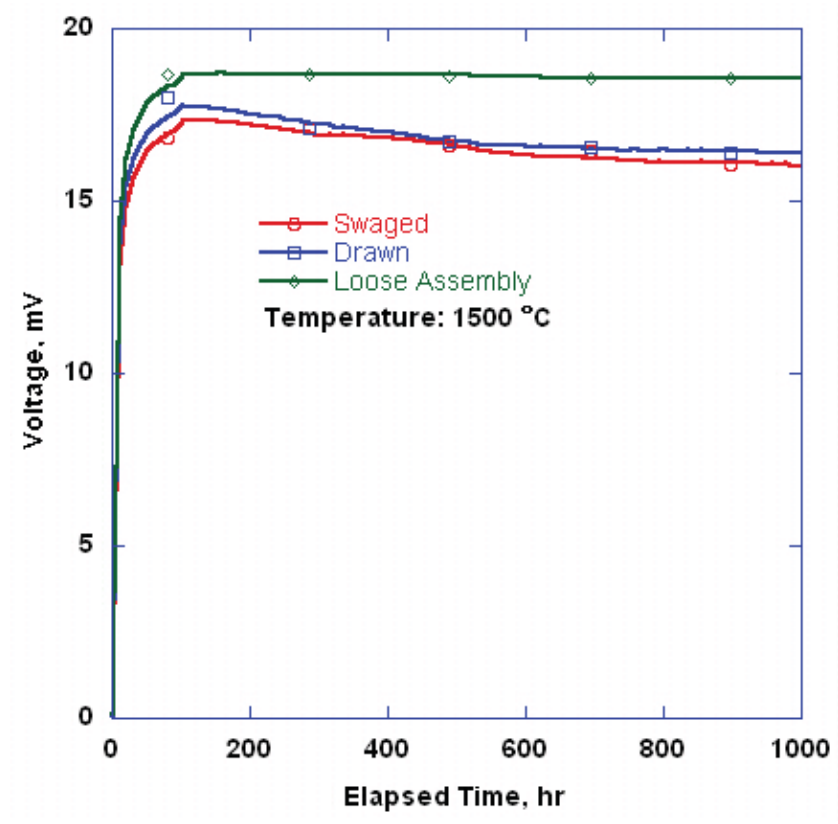

Fig. 3. HTIR-TC performance during 1000 hour test $1500^{\circ} \mathrm{C}$.

HTIR-TCs were installed in a multi-capsule experiment that is currently being irradiated in INL's ATR. This multi-capsule experiment is designed to irradiate samples at temperatures up to $1200{ }^{\circ} \mathrm{C}$. This test, which started in February 2007, is still underway. Fig. 4 shows signals from two INL-developed HTIR-TCs and one Type N thermocouple located within one of the test capsules. Signal variations are due to ATR power fluctuations and outages. As shown in this figure, the HTIRTC (TC-4-1) located near the Type N thermocouple (TC-4-3) is giving a signal consistent with the signal from this Type $\mathrm{N}$ thermocouple at the beginning of this irradiation. In addition, the HTIR-TC located at a higher temperature region within the capsule (TC-4-2) is yielding a consistent, but higher temperature, signal. However, in October 2008, the Type N thermocouple failed and its signal ceased.

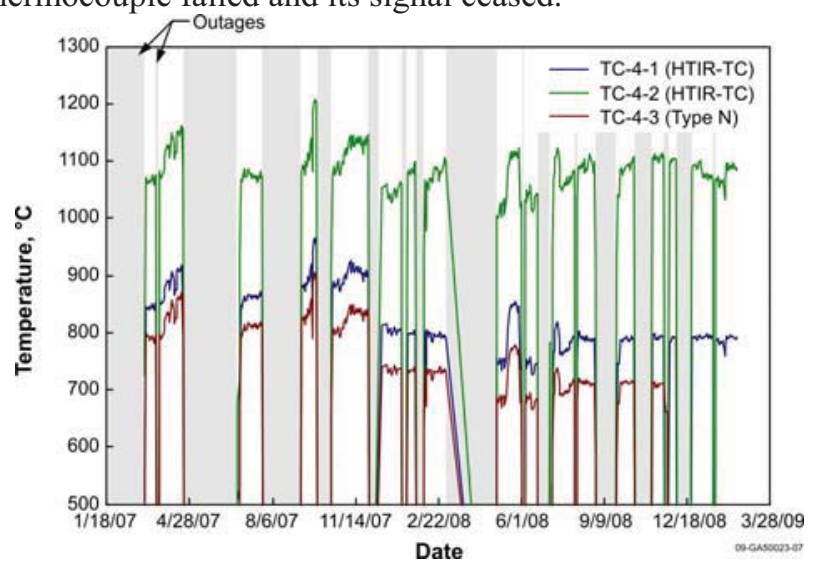

Fig. 4. HTIR-TCs installed in AGR-1 test capsule and representative HTIR-TC and Type N data during ATR irradiation. 


\section{2) Silicon Carbide Temperature Monitors}

For decades, post-irradiation temperature monitors have been based on the phenomenon that irradiation-induced swelling of silicon carbide $(\mathrm{SiC})$ begins to anneal out at temperatures exceeding its irradiation temperature. These $\mathrm{SiC}$ monitors have relied on changes in length, density, thermal conductivity, and electrical resistivity to infer irradiation temperature. However, Snead et al. [11] recommends using changes in resistivity because of improved accuracy, ease of measurement, and reduced costs. Experimental data indicate that accuracies of approximately $20^{\circ} \mathrm{C}$ are possible with this technique for dose ranges of 1 to $8 \mathrm{dpa}$ and temperatures from 200 to $800{ }^{\circ} \mathrm{C}$. Absolute limits for this approach are $150{ }^{\circ} \mathrm{C}$ (an amorphorous threshold) and $875{ }^{\circ} \mathrm{C}$ (due to recrystallization). A capability similar to the technique used described in [11] is being implemented at INL's HTTL. Efforts to prepare and evaluate the equipment setup have recently been completed. Efforts are underway to conduct comparison evaluations with ORNL by comparing results from irradiated $\mathrm{SiC}$ monitors.

\section{B. Thermal Conductivity}

Changes of thermal conductivity in samples irradiated in the ATR are currently evaluated out-of-pile. The labor and time to remove, examine, and return irradiated samples for each measurement makes out-of-pile approaches expensive. In addition, only the sample's endstate is captured after it is removed from the reactor; and multiple removals and reinsertions may disturb the phenomena of interest. Having the capacity to effectively and quickly characterize sample properties during irradiation has the potential to improve the fidelity of data and reduce testing costs.

A joint Utah State University (USU) / Idaho National Laboratory (INL) project, with assistance from the Institute for Energy Technology at the Halden Reactor Project (IFE HRP), has been initiated to investigate in-pile fuel thermal conductivity measurement methods.[15] The methods use a surrogate fuel rod with Joule heating to simulate volumetric heat generation to gain insights about in-pile detection of thermal conductivity. Based on the limited electrical and thermal properties available from vendors, initial investigations have focused on two surrogate materials: CFOAM $^{\circledR}$, a carbon structural foam produced by Touchtone Research Laboratory; and MP35N, a high strength alloy used for many aerospace applications consisting of 35\% nickel, $30 \%$ cobalt, $20 \%$ chromium, and $10 \%$ molybdenum. To compare results from proposed in-pile thermal conductivity measurement methods, detailed temperature-dependent properties were needed for each of these materials. These properties were obtained using thermal property measurement systems (e.g., a pushrod dilatometer system, a laser flash thermal diffusivity measurement system, and a differential scanning calorimetry system) installed at INL's HTTL.

Two methods for in-pile detection of thermal conductivity are being investigated. The first method is a steady state method that utilizes two thermocouples to calculate fuel rod thermal conductivity, one to monitor fuel centerline temperature and another to monitor temperature at a measured radial position within the rod. The method is being tested under several conditions to assess the sensitivity of the measurement. Prior evaluations suggest that a similar method has successfully been applied by the Institute for Energy Technology in the Halden Boiling Water Reactor to detect changes in fuel thermal conductivity during irradiation.[5]

The second method is the Transient Hot Wire Method (THWM), which is an adaptation of the ASTM hot-wire method. In a solid, this method is applied by embedding a line heat source in the material whose thermal conductivity is to be measured. From an initial condition of equilibrium, the heat source is energized and heats the sample with constant power. The thermal conductivity is found from the temperature rise measurement at a small distance from the heat source. Preliminary investigations suggest that this approach may offer certain advantages over two-thermocouple techniques. [16]

Initial USU/INL testing has focused on the two thermocouple method using the setup shown in Fig. 5. Data from this setup are used to quantify parameters in (1) for estimating thermal conductivity, $k$, of a rod, with volumetric heat generation rate, $\dot{q}$, and temperature difference, $\Delta T$, measured by two thermocouples (one located at the center of the rod and one located a distance $r$ from the rod center):

$$
k=\frac{\dot{q} \cdot r^{2}}{4 \cdot \Delta T}
$$

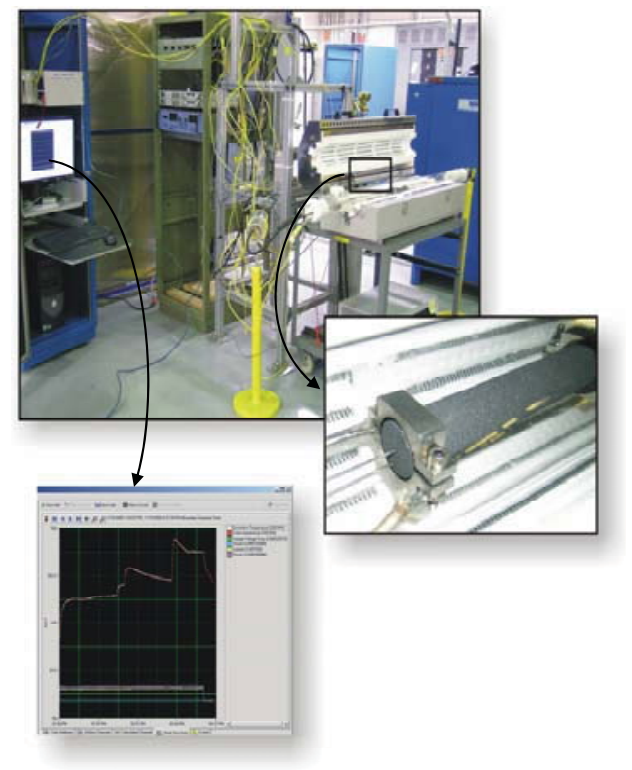

Fig. 5. Setup for evaluating two thermocouple method.

As shown in Fig. 5, the surrogate rod is positioned inside a tube furnace to control temperature and provide a temperature test range from $500{ }^{\circ} \mathrm{C}-700{ }^{\circ} \mathrm{C}$ (the tube furnace is used to establish ambient temperature). A specified voltage and current are supplied to the sample by attaching the power supply to each end of the rod using Inconel electrodes connected to Inconel clamps. Leads attached to Inconel clamps at each end of the surrogate rod allow measurement of the voltage drop across the sample. Current within the experimental test loop is precisely measured using an in-line 
shunt. Volumetric heat generation is calculated from the power, $P$, to the rod, using the measured current $(I)$, the sample voltage drop $(V)$, and rod dimensions. Flow rates can be adjusted using valves to vary fluid conditions within the tube. The fluid inside the tube can either be air or an inert gas, such as argon. Signals are processed by a data acquisition system to record temperatures from thermocouples and power in the rod. Selected data from initial two-thermocouple testing over a temperature range from 500 to $700{ }^{\circ} \mathrm{C}$ with the supplied power held constant at $100 \mathrm{~W}$ are plotted in Fig. 6. Values shown in Fig. 6 differed by $2 \%$ to $8 \%$ from the values obtained using material property measurements systems at INL's HTTL. Sensitivity tests are underway to determine the limitations of this approach. In addition, as noted above, tests will soon be initiated to investigate hot-wire techniques.

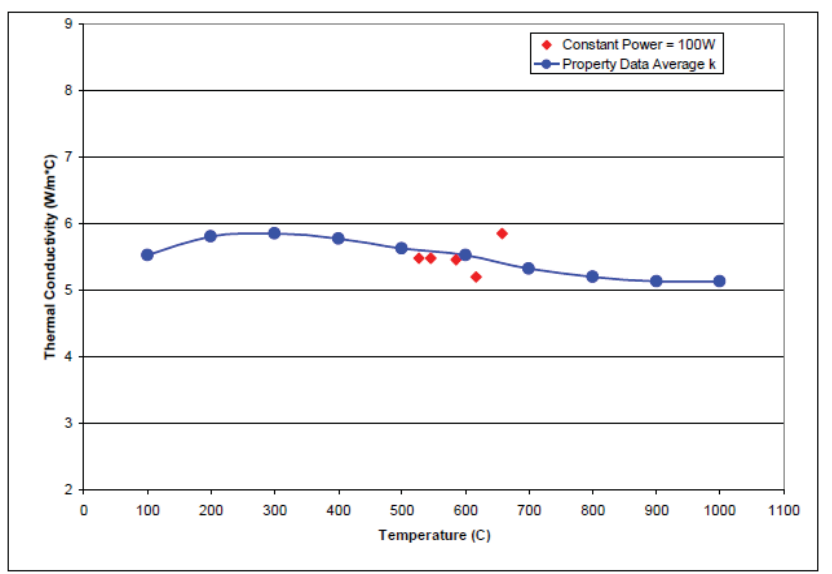

Fig. 6. Comparison of CFOAM25 thermal conductivity data from two-thermocouple approach with average data obtained from laboratory measurement systems.

\section{Dimensions}

Geometry changes of samples irradiated in the ATR are also currently evaluated out-of-pile. However, INL is investigating several options offering the potential to obtain real-time length and diameter data from samples during irradiation. For lower temperature (up to $500{ }^{\circ} \mathrm{C}$ ) applications, efforts are underway to enhance commercially-available Linear Variable Differential Transducers (LVDTs) for ATR applications. Although not discussed in this paper, INL is also investigating ultrasonic transducers as in-pile sensors.

LVDT designs made by vendors offering nuclear grade sensors for irradiations in ATR instrumented capsules and inpile tubes are currently being evaluated at INL [17]. The objective of this effort is to evaluate (and enhance, as needed) the viability of applying commercially available LVDTs as inpile sensors for detecting dimensional changes of specimens during lower temperature (up to $500{ }^{\circ} \mathrm{C}$ ) irradiations in ATR instrumented lead capsules and PWR loop tests. Table II lists desired LVDT characteristics for ATR irradiation.
TABLE II

DESIRED ATR LVDT CHARACTERISTICS

\begin{tabular}{|c|c|}
\hline Parameter & ATR Specification \\
\hline Total LVDT Displacement (stroke), $\mathrm{mm}$ & $> \pm 2.5$ \\
\hline Resolution, $\mathrm{mm}$ & $10^{-2}$ \\
\hline Sensitivity, V/m & $>50$ \\
\hline Maximum operating temperature, $\mathrm{K}$ & 773 \\
\hline Normal operating pressure, $\mathrm{MPa}$ & $0.1013-15.5$ \\
\hline Peak thermal flux, $\mathrm{E}<0.625 \mathrm{MeV}$, neutrons $/ \mathrm{cm}^{2} \mathrm{~s}$ & $1 \times 10^{14}$ \\
\hline Thermal fluence, $\mathrm{E}<0.625 \mathrm{MeV}$, neutrons $/ \mathrm{cm}^{2 \mathrm{a}}$ & $8 \times 10^{21}$ \\
\hline Peak fast flux, E $>20 \mathrm{MeV}$, neutrons $/ \mathrm{cm} \mathrm{cm}^{2 \mathrm{a}}$ & $3 \times 10^{14}$ \\
\hline Integrated fast fluence, $\mathrm{E}>20 \mathrm{MeV}$, neutrons $/ \mathrm{cm}^{2 \mathrm{a}}$ & $2 \times 10^{22}$ \\
\hline Integrated gamma exposure, $\gamma / \mathrm{cm}^{2 \mathrm{a}}$ & $9 \times 10^{22}$ \\
\hline Maximum LVDT Diameter, $\mathrm{mm}$ & $<25.4$ \\
\hline Maximum LVDT Length, mm & 63.8 \\
\hline Test environment & $\begin{array}{l}\text { Water and Inert Gas } \\
\text { (Neon, Helium) }\end{array}$ \\
\hline
\end{tabular}

Two vendors were identified as having the potential to make nuclear-grade commercial LVDTs to Table II specifications. One vendor's design requires that the LVDT diameter exceed values desired for ATR applications; while the other vendor's design has a peak operating temperature of $350{ }^{\circ} \mathrm{C}$. LVDTs made by each vendor were evaluated at the HTTL using test setups shown in Fig. 7. To verify the accuracy for the range of elongations anticipated, calibration tests were completed between room temperature and $500{ }^{\circ} \mathrm{C}$. Long duration performance evaluations were then completed to monitor signal stability at $500{ }^{\circ} \mathrm{C}$ for 1000 hours. Detailed results from all the evaluations are reported in [17]; long duration testing results are summarized below.
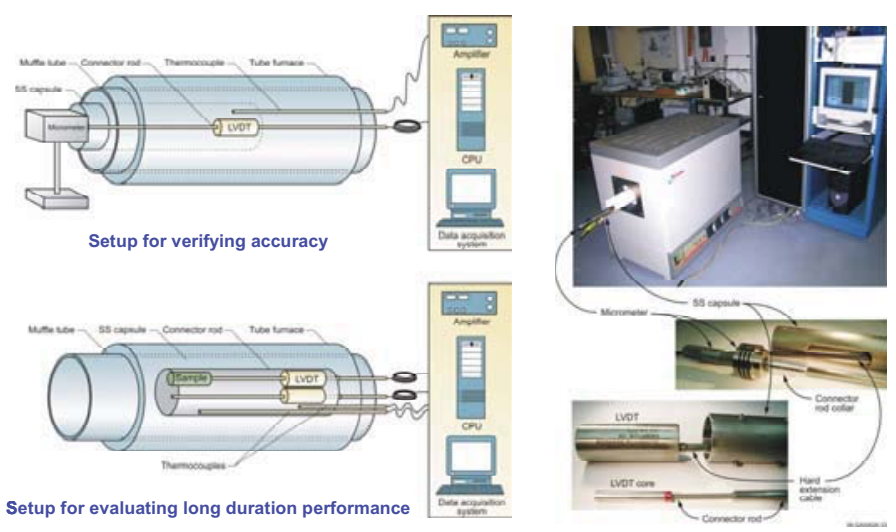

Fig. 7. Setup for evaluating LVDT performance.

For the long duration test, all four LVDTs were configured in the test fixture with cores set as close as possible to null positions. Consequently, output for all four LVDTs would be expected to remain near $0 \mathrm{Vdc}$ throughout the test (if they remained stable). For comparison purposes, $500{ }^{\circ} \mathrm{C}$ calibration data for each LVDT were used to convert measured output voltage to an indicated displacement. Fig. 8 presents the deviation of the indicated displacement (relative to the time 0 
output) as a percentage of linear travel (which is $+/-2.5 \mathrm{~mm}$ for all sensors).

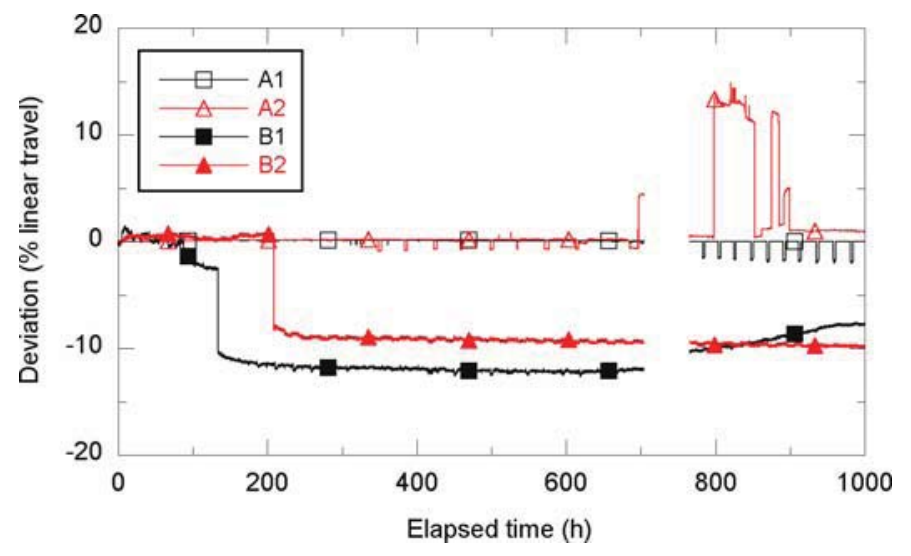

Fig. 8. LVDT response during long duration testing.

As indicated in Fig. 8, Vendor A LVDTs were found to be superior to Vendor B LVDTs. Their maximum deviation was equivalent to a displacement of $\sim 7 \times 10^{-6} \mathrm{~m}$ relative to their time 0 position. (Approximately $25 \mathrm{~h}$ were set aside for stabilization at $500{ }^{\circ} \mathrm{C}$ before marking time 0 .) Results for Vendor B LVDTs are quite different. These LVDTs show substantial oscillation in addition to dramatic step changes in indicated deviations (near $130 \mathrm{~h}$ for LVDT B1 and near $210 \mathrm{~h}$ for LVDT B2). In fact, LVDT B1 shows a maximum deviation equivalent to a displacement of $\sim 700 \times 10^{-6} \mathrm{~m}$, indicating a reduction in stability by a factor of $\sim 100$ compared to Vendor A LVDTs. These results, along with calibration evaluations documented in [17] clearly favor the Vendor A LVDT design for use in ATR irradiation experiments.

However, several options are being pursued to enhance Vendor A LVDT designs. For example, components used in LVDTs developed for INL's Loss of Fluid Test [17] were found to produce LVDTs with stable signals up to $500{ }^{\circ} \mathrm{C}$. Once fabrication efforts of developmental nuclear grade LVDTs that include such components are completed, these LDVTs will be evaluated at INL's HTTL. Test results from evaluations of developmental and commercially-available nuclear grade LVDTs will ultimately be used to select an optimized LVDT design for ATR irradiations.

\section{CONCLUSIONS}

An effort is underway to provide enhanced in-pile instrumentation for ATR users. Development of sensors capable of providing real-time measurements of key parameters during irradiation is emphasized because of their potential to offer much-improved irradiation performance data and reduce post-test examination costs. The effort to enhance ATR instrumentation began by completing a review to identify what instrumentation was available at other test reactors. Developmental or non-nuclear technologies that could be used in ATR irradiation tests were also considered. Instrumentation development activities were then prioritized based on anticipated near-term customer needs and technology readiness. In addition, instrumentation development collaborations were begun with other organizations that employ similar sensors in their test facilities. This effort has resulted in new sensors now being available to ATR NSUF users and other research organizations. Representative results from on-going INL efforts to evaluate sensors for detecting temperature and geometry changes during irradiation testing illustrate the process used within this project.

\section{REFERENCES}

[1] "FY2008 Advanced Test Reactor National Scientific User Facility User's Guide," INL/EXT-07-13577, Idaho National Laboratory (2007).

[2] J. F. Villard and M. Schyns, "Adavnced In-pile measurements of fast flux, dimensions and fission gas release," Proc. ANS NPIC HMIT 2009 Topical Meeting, Knoxville, TN, April 2009.

[3] J. F. Villard, "INSNU Project - Instrumentation for irradiation experiments in research reactors," Proc. ANS NPIC HMIT 2009 Topical Meeting, Knoxville, TN, April 2009.

[4] G. Cheymol, H. Long, J-F. Villard, and B. Brichard, "High level gamma and neutron irradiation of silica optical fibers in CEA OSIRIS nuclear reactor," IEEE Transactions on Nuclear Science, Vol. 55, No. 4, August 2008, pp 2252-2258.

[5] S. Solstad and R. Van Nieuwenhove "Instrument Capabilities and Development at the Halden Reactor Project" Proc. ANS NPIC HMIT 2009 Topical Meeting, Knoxville, TN, April 2009.

[6] P. Bennett, "In-core measurements of fuel-clad interactions at the Halden reactor," IAEA Technical Meeting on Fuel Rod Instrumentation and In-Pile Measurement Techniques, Halden, Norway, 3-5 September 2007.

[7] Email from K. Bakker, NRG, Petten, Netherlands, to J. Rempe, INL, dated December 11, 2007.

[8] B. G. Kim, et al., "Status and perspective of material irradiation tests in the HANARO," Proc. 1st International Symposium on Materials Testing Reactors, JAEA-Oarai, Japan, July 2008.

[9] G. Proctor, "In-reactor pressure vessel measurements for the PBMR DPP," 3rd International Topical Meeting on High Temperature Reactor Technology (HTR2006), Johannesburg, South Africa, October 1-4, 2006.

[10] M. Narui, T. Shikama, M. Yamasaki,k and H. Matsui, "Development of high-temperature irradiation techniques utilizing the Japan Materials Testing Reactor," Basic Studies in the Field of High Temperature Engineering, Second Information Exchange Meeting, Paris, France, 1012 October, 2001, pp. 145-152.

[11] L L. Snead, A. M. Williams, and A. L. Qualls, "Revisiting the use of $\mathrm{SiC}$ as a post-irradiation temperature monitor," Effects of Radiation on Materials, ASTM STP 1447, M L. Grossbeck, Ed, ASTM International, West Conshohocken, PA, 2003.

[12] J. L. Rempe, D. L. Knudson, K. G. Condie, S. C. Wilkins, J. C. Crepeau, and J. E. Daw, "Options Extending the Applicability of High Temperature Irradiation Resistant Thermocouples," invited paper for NURETH12 Special Edition, Nuclear Technology, 167, July 2009.

[13] J. L. Rempe, D. L. Knudson, K. G. Condie, and S. C. Wilkins, "Thermocouples for high-temperature in-pile testing," Nuclear Technology, 156, No. 3, December 2006, pp 320-331.

[14] J. E. Daw, J. L. Rempe, D. L. Knudson, S. C. Wilkins, and J. C. Crepeau, "High Temperature Irradiation-Resistant Thermocouple performance improvements," Proc. ANS NPIC HMIT 2009 Topical Meeting, Knoxville, TN, April 2009.

[15] B. Fox, H. Ban, J. Rempe, D. Knudson, and J. Daw, "Development of an in-pile technique for fuel thermal conductivity measurement," Proc. ANS NPIC HMIT 2009 Topical Meeting, Knoxville, TN, April 2009.

[16] J. L. Rempe, K. G. Condie, and D. L. Knudson, Thermal Properties for Candidate SCWR Materials, INL/EXT-05-01030, December 2005.

[17] D. L. Knudson and J. L. Rempe, "LVDT evaluations for ATR irradiations," Proc. ANS NPIC HMIT 2009 Topical Meeting, Knoxville, TN, April 2009.

[18] J. R. Wolf, "The Linear Variable Differential Transformer and its uses for in-core fuel rod behavior measurements," Proc. International Colloquium on Irradiation Tests for Reactor Safety Programmes, June 25-28, 1979, Petten, The Netherlands. 